\title{
REVIEW
}

\section{Analysis of Manufacturing Technology for Light Sport Aircraft Composite Materials}

\section{Rong $\mathrm{Li}^{1}, \mathrm{Zi}-\mathrm{Han} \mathrm{Lu}^{2 *}$}

1. Department of Aircraft Manufacturing Engineering, College of Flight Vehicle, Xi'an Aeronautical University, Xi'an 710077, Shaanxi, China.

2. School of Architecture and Civil Engineering, Xi'an University of Science and Technology, Xi'an 710077, Shaanxi, China.

Corresponding Author: Zi-Han Lu, School of Architecture and Civil Engineering, Xi'an University of Science and Technology, Xi'an Yanta Road No.58, Xi’an 710077, Shaanxi, China. E-mail: 15829738599@163.com

\footnotetext{
Abstract

Light sport aircraft generally refers to single-seat or two-seat light aircraft with a take-off weight of less than $600 \mathrm{~kg}$. With the characteristics of simple structure and low price, it has developed rapidly in recent years. One of the key points in the design and manufacture of light sport aircraft is to reduce the cost of structure manufacture. Therefore, composite materials are widely used. It not only reduces the weight of aircraft structure, but also reduces the cost. Combined with the structural characteristics of light sport aircraft, the material manufacturing process is analyzed, and the application of different processes in light sport aircraft is compared to determine the best manufacturing process plan.

Keywords

Light sport aircraft; composite materials; production process
}

\section{INTRODUCTION}

As a new kind of material, composite material has been widely used in many industries, especially in aerospace structure. Composite materials can reduce the weight and size of the aircraft structure, achieve high-energy development more effectively, and reduce the life cycle cost of the aircraft. Based on the structural characteristics of DF2 composite wings of light sport aircraft, finite element software was applied to establish a finite element model of the structural scheme, and the advantages and disadvantages of different design schemes were analyzed and compared to optimize the structural design. While ensuring the structural performance of the aircraft, the manufacturing cost is reduced.

\section{STRUCTURAL FEATURES OF LIGHT SPORT AIRCRAFT}

The maximum take-off weight of light sport aircraft is within $600 \mathrm{~kg}$, the maximum flight speed is within $222 \mathrm{~km} / \mathrm{h}$ and the stall speed is within $83 \mathrm{~km} / \mathrm{h}$. It is single or two-seater, with fixed landing gear, a propeller with an immutable pitch or ground pitch adjustment, and an electric motor or piston engine as a power unit ${ }^{[1]}$. At present, the development of light sport aircraft in China is

(C) The Author(s) 2019. Open Access This article is under the terms of Creative Commons Attribution 4.0 International License (https://creativecommons.org/licenses/by/4.0/), which permits unrestricted use, sharing, adaptation, distribution and reproduction in any medium or format, as long as you give appropriate credit to the original author(s) and the source, provide a link to the Creative Commons license, and indicate if changes were made. 
still a blank. However, the advanced manufacturing industry has the conditions to produce light sport aircraft at a lower cost. For example, Ningbo Dongfeng Aircraft Co., Ltd. independently developed the DF2 material-compatible two-seater light sports aircraft (Figure 1), and produced a prototype for test flight in July 2008. The DF2 aircraft is designed and manufactured with full composite materials. The main bearing structure is carbon fiber material. Although some achievements have been made, there is still room for improvement ${ }^{[2]}$. Composite materials are widely used in the field of aviation and aerospace. The application of composite materials in aircraft is increasing gradually, and the design and application of main bearing structure is realized. In order to further optimize the design and manufacture of light sport aircraft, the idea of integrating design, material selection and technology can be applied to realize joint cost control. Taking DF2 light sport aircraft as an example, different composite wing structures were designed and compared. In addition, finite element analysis and layering thickness optimization were carried out for different wing structure schemes to determine the optimal design scheme and improve the design effect of composite aircraft.

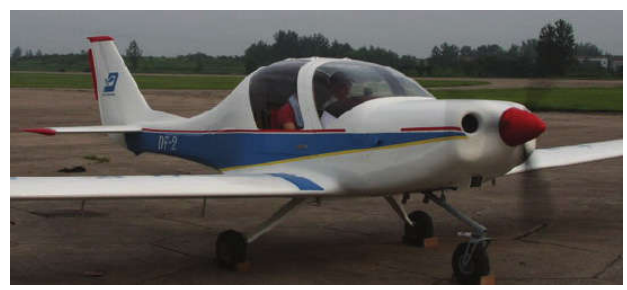

Figure 1 DF2 composite light sport aircraft

\section{CHARACTERISTICS AND PERFORMANCE ADVANTAGES OF COMPOSITE MATERIALS}

\subsection{Composite Material}

A polyphase solid material composed of two or more substances with different physical and chemical properties is a composite material. Although each component material remains relatively independent, the overall performance is not a simple sum of the properties of various materials. In contrast, it has been further improved and optimized ${ }^{[3]}$. For composite materials, usually one phase is the continuous phase as the matrix, and the other phase is the dispersed phase, that is, the reinforcing material. At present, the composites used in light sport aircraft are mainly fiber reinforced composites. The reinforced fiber is the main bearing body of the composite material, and the determination of fiber species and volume content can effectively evaluate the mechanical properties of the composite material along the direction of the fiber. The composite materials used in aircraft structures can be subdivided into glass fiber composites, carbon fiber composites and organic fiber composites according to the types of fibers. The composite material matrix used in light sport aircraft structures is a resin matrix. In the process of manufacturing and forming the material components, the resin matrix is gradually solidified by chemical reaction, which meets the requirements of aircraft structural design. The earliest composite material used for aircraft structures is a resin matrix, which has optimized molding process performance, good moisture and heat resistance, simple subsequent maintenance and low cost. Its advantages are obvious in practical applications.

\subsection{Performance Advantages of Composite Materials}

\subsubsection{Low Quality}

The factors that need to be analyzed in the selection of aircraft manufacturing materials are strength, weight and cost. Compared with traditional metal materials, composite materials have higher specific strength. Composite structures are much lighter than metal structures at the same strength. For example, replacing aluminum parts with composites could reduce the weight of aircraft structures by about 20\%. Moreover, the manufacturing technology of composite materials in China is constantly updated and improved, and more types of composite materials are available. The price of high-strength and high-modulus fiber raw materials such as carbon fiber has continued to decrease, which has led to the strength-price ratio of composite materials exceeding aluminum materials. With the same structural strength, the cost of raw materials for composite components is lower than that of traditional metal components.

\subsubsection{Low Cost}

The manufacturing cost of the sports aircraft structure includes the cost of raw materials, parts processing and component assembly. All parts are assembled according to professional specifications by means of riveting, bolting, welding and gluing. The 
cost of labor and time is huge. Compared with traditional metal materials, complex structures can be formed at one time in the manufacturing process of composite materials, which greatly saves the time needed for parts assembly and labor costs, and does not need to deal with bolts, rivets and other connecting parts. The cost is less and the total weight of the structure is greatly reduced.

\subsubsection{Low Resistance}

Composite materials are used to make light sport aircraft, because rivets are not used in the skin, the fuselage surface is smoother, and there is less resistance during the flight. Taking the four-seat composite airplane LancairIV and the four-seat allmetal airplane Cessna182 as examples, the equivalent flat resistance areas are $0.197 \mathrm{~m}^{2}$ and $0.557 \mathrm{~m}^{2}$, respectively. According to NACA4412 airfoil analysis, smooth airfoil $\mathrm{CL}$ smooth $=1.55, \mathrm{CD}$ smooth $=0.010$, surface rough airfoil $\mathrm{CL}$ rough $=1.28$, $\mathrm{CD}$ rough $=0.010$. Assuming the surface of the wing is smooth, it can be determined that the wing area can be reduced by $17 \%$ according to the formula (1). Likewise, as the wing area decreases, so does the structural weight of the aircraft. In addition, to a certain extent, it can also reduce the difficulty of aircraft wing processing and manufacturing and assembly technology, thus further reducing the related costs.

$$
\frac{S_{\text {wingrough }}-S_{\text {wingsmooth }}}{S_{\text {wingrough }}} \times 100 \%=\frac{C_{\text {Lsmooth }}-C_{\text {Lrough }}}{C_{\text {Lsmooth }}} \times 100 \%=17 \%
$$

Compared with light sport aircraft with the same aerodynamic shape and takeoff weight, the aircraft made of composite skin has less resistance in flight. According to the formula (2), it can be determined that the piston engine output power $\mathrm{P}$ is reduced, and the fuel consumption is reduced, so that the corresponding range of the aircraft is increased.

$$
P=\frac{T V}{\eta}=\frac{D V}{\eta}
$$

\section{COMPOSITE MATERIAL MANUFACTURING PROCESS}

\subsection{Production Process Analysis}

The manufacturing process of composite materials is to transform raw materials into structures and realize the transformation of design structure drawings to physical objects. After the mechanical properties of the composite materials are determined, it is necessary to define the molding and curing process. The molding and curing process can be divided into two parts: molding and curing. Molding is to lay the fiber fabric into a certain shape according to the product design requirements, and brush the mixture of resin and curing agent. Curing is to promote the laminated materials that have been laid into a certain shape to fix the shape under appropriate temperature, time, pressure and other conditions to ensure that the product meets the design basic performance requirements ${ }^{[4]}$. After years of continuous development, the manufacturing process of composite materials has been a major breakthrough, such as hand paste molding process, vacuum assisted molding process, heat tank molding process, winding molding process and prepreg vacuum bag pressing molding process. For light sport aircraft, composite materials must be able to reduce the weight of the aircraft structure and manufacturing costs. Therefore, vacuum assisted molding and prepreg vacuum bag pressing are widely used in this field, and good results have been achieved. Compared with the manufacturing process of metal materials, there are great differences in the forming process of resin base conforming materials: (1) to realize the fiber laying direction determined by the structure design; (2) hot pressing process molding, structural parts molding and material formation completed at the same time; (3) it can meet the basic requirements of large-scale construction and overall molding, and reduce the workload of machining and assembly. (4) gradually improve the process quality control system to maintain a high yield ${ }^{[5]}$.

\subsection{Common Production Process}

\subsubsection{Hand Lay-up Process}

Hand paste molding process can be said to be the highest manufacturing process of composite materials, which can be divided into dry layering molding and wet layering molding. The two methods are:

(1) Dry layering molding manually applies prepreg in the mold layer by layer to the required thickness (required degree) according to the predetermined direction and sequence, obtains the prepreg, and bags the resulting prepreg, then gives the heating and pressure curing, and finally takes off the mold to obtain the composite product ${ }^{[6]}$. Compared with traditional fiber 
fabrics, the application of prepreg can more flexibly control the rubber content of the product and improve the stability of product quality. Because the prepreg fibers and resin are fully wetted, there is no twisting of the fabric fibers during the brushing stage. At the same time, the process of mixing curing agent in the resin can be omitted to reduce the failure of curing due to excessive or insufficient curing agent. In addition, the contact of workers with resin, curing agent and other chemicals in the process of manufacturing is greatly reduced, which improves the safety of operation.

(2) Wet layering molding. The resin mixture containing curing agent is evenly brushed on the mold, and the fiber fabric cut in advance is laid on the mold according to the requirements, and the fabric is extruded with a brush or scraper. After sufficient glue soaking and bubble elimination, the resin mixture is brushed again and the second layer of fiber fabric is laid. The above processes are repeated until the design thickness is reached ${ }^{[7]}$. Finally, the treated composite material is heated and solidified under appropriate pressure conditions, or the heat released during the curing process of the resin system is used for curing and molding, and finally the finished product is obtained by demoulding. As shown in Figure 2, the fiber fabric can be divided into unidirectional fiber fabric and orthogonal fiber fabric according to the trend of the fiber. Therefore, the strength and stiffness of composite material components, especially those made as raw materials, are relatively large in this direction, while their mechanical properties are relatively poor in the two directions. The fibers of the orthogonal fiber fabric are arranged at a ratio of about $50 \%$ to $90^{\circ}$, and the composite materials made of the orthogonal fiber fabric have good mechanical properties in both directions. Among them, the tensile strength and stiffness of the orthogonal fiber composite are lower when it is $45^{\circ}$ from the 1 direction, but it has good shear strength and stiffness ${ }^{[8]}$.

\subsubsection{Vacuum Assisted Resin Infusion Molding Process}

The vacuum assisted resin infusion molding process is also known as the VARI molding process, that is, a flexible vacuum bag film or a sealed fiber reinforced material is used to cover a single-sided rigid mold, and all the gas in the mold cavity is evacuated under the vacuum negative pressure condition. Through resin flow and penetration, the fiber material and its fabric are effectively infiltrated, and finally cured and molded at room temperature or under heating. This manufacturing process for composite materials requires the application of a low-viscosity and curable resin matrix at room temperature, and the lowviscosity plateau time before the resin gel is long enough to allow sufficient operating time. In addition, it is necessary to ensure good sealing conditions, maintain a high vacuum, and promote the effective discharge of bubbles, so as to minimize the porosity of products. The molding thickness is reasonably selected. Previous research results show that the resin can completely penetrate the board, the resin content of the laminate can be controlled below $38 \%$, and the glue content of the sandwich board can be controlled at about $60 \%$. However, the weight exceeded the design maximum, which could not meet the take-off requirements of light sport aircraft, and further adjustment and optimization of the existing process were needed ${ }^{[9]}$.

\subsubsection{Vacuum Bag Only Compression Molding Process for Prepreg}

Prepreg vacuum bag only pressing process is also known as VBO molding process, which is to apply flexible vacuum bag film coating or sealing line to the single-sided rigid mold for reinforcement material treatment, and in the vacuum state of negative pressure to the mold cavity of all the gas discharged. Finally, it is cured and shaped at a specific curing temperature in an oven. In actual production, the rubber content of the prepreg can be flexibly adjusted according to demand, and the resin content of the foam sandwich panel can be effectively controlled according to this. According to the existing research results, the surface of the sandwich panel manufactured by the prepreg vacuum bag compression molding process is smooth, and the numerical rubber content can be flexibly controlled, which can meet the take-off weight requirements of light sports aircraft.

\section{OPTIMUM DESIGN OF COMPOSITE WING STRUCTURE}

\subsection{Design Principles of Wing Structure}

The design of the composite material wing structure of the light sport aircraft is not much different from the metal wing design. The basic principles must be adhered to when designing and manufacturing. It mainly includes the following aspects:

(1) Least resistance principle. The wing is the main structure of the aircraft to generate lift. The core requirement of the design is aerodynamics. It is required to reduce all kinds of resistance to the maximum extent while maintaining sufficient lift. The aircraft wing shape parameters are optimized, including the chord number $\lambda$, relative thickness $\bar{c}$, sweepback angle $\mathrm{x}$, trapezoidal ratio $\eta$, and various attached wing parameters. The strength, stiffness, shape accuracy and surface smoothness of the 
wing structure are comprehensively designed to meet the aerodynamic shape requirements of the wing.

(2) Excellent performance principle. In order to improve the durability and damage tolerance characteristics of the wing structure, it is necessary to comprehensively optimize the design of the stress member layout, connection design, and detail design to improve the overall performance of the wing structure. At the same time, structural geometry, structural layout, stress state, aeroelasticity and other requirements are comprehensively analyzed to ensure the proportion and amount of composite materials in the application of wing structure, so as to maximize the advantages of composite materials to the aircraft and improve the application efficiency of materials ${ }^{[10]}$.

(3) Application security. For composite materials, its performance is highly dispersive, and errors are easy to occur in calculation. Therefore, in the design and manufacturing process, for the composite wing structure, especially the main loadbearing structure, it is necessary to do test verification in advance. After a comprehensive analysis of the results and calculation, the structural strength and stiffness performance parameters are determined to improve the safety of aircraft composite structure design.

\subsection{Design Optimization of Laminate Structures}

When designing a laminate structure for a given ply angle $\left(0^{\circ}, 90^{\circ}, \pm 45^{\circ}\right)$, four ply direction angle thicknesses can be determined as design variables. Under the set constraints, the structural weight is guaranteed to be the lightest, and a mathematical model for optimal design is established:

Take $\mathrm{t}_{0}, \mathrm{t}_{90}, \mathrm{t}_{45}, \mathrm{t}_{-45}$ as design variables,

then, $\left\{\begin{array}{l}\min f(x) \\ \text { s.t.g }{ }_{j}(x) \leqslant 0(j=1,2, \cdots, \mathrm{m})\end{array}\right.$

With the structural weight as the objective function, based on constraints such as strength, stiffness, and stability, the design of the optimal number of layers (layer thickness) is completed. Finally, the basic principles of composite laminate layering are combined to complete the process design.

\subsection{Structural Design of Composite Materials}

\subsubsection{Wing Structure}

There are three types of wing structure: single beam, double beam and multi - wall. (1) The single-beam wing structure is the layout of the front beam and rear wall. The front beam is located $25 \%$ from the leading edge, and the rear wall is $70 \%$ from the leading edge. They are all longitudinally stressed components of the wing skeleton, which together form a torsion-resistant closed chamber for transmitting the wing load. Six wing ribs are arranged along the span direction, no reinforcement ribs are required, and there is no stringer on the skin. (2) Double beam wing, that is, the front beam is located $25 \%$ from the leading edge, and the rear beam is located $65 \%$ from the leading edge. They are all longitudinally stressed components of the wing skeleton, which together form a torsion-resistant closed chamber for transmitting the wing load. Six wing ribs are arranged along the span direction, no reinforcement ribs are required, and there is no stringer on the skin. (3) Multi-wall wing, that is, five walls are set at $20 \%$ and $80 \%$ of the leading edge, to form an anti-torsion closed chamber. The transverse members are root ribs and sharp ribs, without reinforcing ribs, and no stringer is set on the skin.

\subsubsection{Design of Structural Details}

(1) Wing beam. The whole carbon fiber composite structure of "[" type shall be used as the main longitudinal load-bearing component of the wing beam, and its rigidity and strength shall be controlled. The spar length and beam height are designed according to the requirements. A total of 40 layers of edge slabs are set with a thickness of $6 \mathrm{~mm}$. The web layer is designed as 20 layers with a thickness of $3 \mathrm{~mm}$. (2) Wall. The wall structure is a longitudinally-stressed member, which is a wing beam that weakens the edge strips. In actual design, to facilitate the finite element analysis, the edge strips are ignored, and the wall is considered as the web structure design. A total of 26 layers of paving walls were set up with a thickness of 3.9mm. (3) Wing rib. The rib is a transverse load-bearing component, and 5 ribs are designed, which are distributed along the spanwise direction. Because the honeycomb sandwich structure is applied, the wing ribs can be directly considered as the web structure design without considering the edge strip. In addition, in order to reduce the difficulty of calculation, the same form is used for laying, with a total of 15 layers and a thickness of $8.1 \mathrm{~mm}$. (4) Thin-gauge skin. As the surface part of the wing, it is mainly 
used to maintain the shape of the wing, which needs to directly bear the aerodynamic load and needs to be transferred to the longitudinal and transverse members of the wing. The wing skin of the light sport aircraft used in this study is a honeycomb sandwich structure, with a total of 15 layers of pavement, a thickness of $8.1 \mathrm{~mm}$, and a honeycomb core height of $6 \mathrm{~mm}$.

\subsection{Analysis of Wing Structure}

The finite element model of aircraft composite wing structure was established and analyzed by professional software. Composite laminate structures can be simulated using plate and shell elements. At the same time, because of the simplified model and the requirements of the composite material process, the ribs and wall edges are directly ignored, and there are no rod elements. The aircraft is a fully composite material structure, and the integrated molding process is used. There is no need to consider rivets, bolt connectors and other components in the whole structure. Through the finite element model analysis, under the same working condition, the single beam wing, double beam wing and multi wall wing of composite aircraft have the most serious displacement at the slightly trailing edge of the wing, and the stress at the restrained part of the wing root is the largest. After buckling stability analysis, it can be determined that the maximum equivalent stress of the three structures is less than the material yield limit, which can meet the structural strength design requirements of light sport aircraft wings. Three different wing structure forms can be determined through comprehensive analysis. The first two rear wall structure forms have the lightest wing mass. The absolute value of the wing buckling factor in the form of a single-beam double-wall structure is large. Under the same conditions of structural strength and stiffness, its structural stability is stronger.

\section{CONCLUSION}

The advantages of composite materials in light sports aircraft structures are obvious. It can reduce structural weight and cost. Further research and analysis on its manufacturing process is of great significance to promote the manufacturing application of light sports aircraft. There are few researches on composite materials of light sport aircraft in China. On the current basis, continuous research and development should be carried out to achieve greater results.

\section{REFERENCE}

[1] Zhang XL, Huang WH, Fang CW, Li CY. Research on buckling and post-buckling of aircraft composite stiffened slab structure. Computer Simul:1-6.

[2] Mao YQ, Yang F, Wang L. Static Strength Load and Experimental Study of Composite Wing of M2 Aircraft. Aviat Eng Prog 2019,10(05):643-649.

[3] Chen ZW, Ren QL, Pang L, Xue SX, Chen B, Wu ZQ. Development of precision water cutting equipment for large-scale carbon fiber composite aircraft skin components. Fluid Machinery 2019,47(09):12-16+26.

[4] Zhang JH. Application of advanced composite materials in aircraft structures. Chem Des Newsl 2019,45(09):44-45.

[5] Xiong J, Zhao XX, Li HM, Wu B. Design and verification of composite structure of twin-engine general aircraft. Hi Tech Fibers Appl 2019,44(04):35-40.

[6] Cao JB. Research on Localization Application Technology of Aircraft Structural Composite Materials. Chinese Society of Aeronautics and Astronautics. Proceedings of the 4th China Aviation Science and technology conference in 2019. Chinese Society of Aeronautics and Astronautics: Chinese Society of Aeronautics and Astronautics 2019:6.

[7] Shu MJ, Li YZ, Liu C. Research on manufacturing technology of composite material for Light Sport Aircraft. Heilongjiang Sci Technol Inf 2017(06):7.

[8] Zhang YL. Research on the composite structure design of Light Sport Aircraft. Nanjing University of Aeronautics and Astronautics 2009.

[9] Liang HZ. Optimization design of composite wing structure of DF-2 Light Sport Aircraft. Nanjing University of Aeronautics and Astronautics 2009.

[10] Li W. Research on the integration of structural design, material and technology of Light Sport Aircraft Composite. Nanjing University of Aeronautics and Astronautics 2009. 